\title{
Foreword of the Fifth Symposium on Nuclear Analytical Chemistry (NAC-V)
}

\author{
R. Acharya · A. Goswami $\cdot$ A. V. R. Reddy
}

Received: 8 September 2014/Published online: 7 November 2014

(c) Akadémiai Kiadó, Budapest, Hungary 2014

\begin{abstract}
The Fifth Symposium on Nuclear Analytical Chemistry (NAC-V) was organized at BARC, Mumbai during January 20-24, 2014 with more than 300 participants. It was sponsored by the Board of Research in Nuclear Sciences, Department of Atomic Energy (DAE), India and organized in cooperation with the IAEA and coorganized by the IANCAS. A total of 240 contributed abstracts along with 27 invited talks and 10 invited short talks were presented in 15 technical sessions. Selected 54 full papers of NAC-V have been accepted after review for publication in special issue of JRNC.
\end{abstract}

Keywords NAC-V . Foreword · Technical program · JRNC publications

Chemical characterization of materials is the most important step of chemical quality control (CQC) and conventional wet chemical as well as spectrochemical techniques are routinely used for this purpose. But these techniques need chemical dissolution of samples, which is tedious and needs special care in many cases while dealing trace and sub-trace elements as it is not free from reagent blanks. Besides, solid samples like metals and alloys, glass and ceramics that are difficult for chemical dissolution need to be analyzed by suitable non-destructive methods and capable of simultaneous multielement determination at major to sub-trace

R. Acharya $(\bowtie) \cdot$ A. Goswami · A. V. R. Reddy Bhabha Atomic Research Centre, Department of Atomic Energy, Government of India, Trombay, Mumbai 400085, India e-mail: racharya@barc.gov.in

A. Goswami

e-mail: agoswami@barc.gov.in

A. V. R. Reddy

e-mail: avreddy@barc.gov.in concentration levels. Nuclear Analytical Techniques (NATs) meet these requirements. Horizons of NATs expanded by leaps and bounds with the availability of nuclear reactors, particle accelerators, rapid development in semiconductors \& electronics and hand-held devices. NATs find applications in all branches of science and technology due to their properties like simultaneous multielement capability, inherent accuracy, precision and selectivity. Neutron and proton based techniques in conjunction with high resolution gamma-ray spectrometry are capable of determining almost all the elements from hydrogen to uranium. NATs can also be effectively employed for nondestructive determination of trans-uranium elements. Techniques like activation analysis using neutrons (NAA and PGNAA), charge particles like proton and alpha (CPAA) and photon (PAA), ion beam analysis (PIXE, PIGE, RBS and NRA) and X-ray Fluorescence (XRF, EDXRF and TXRF) are extensively used in various $R \& D$ programs as well as for material characterization in nuclear technology. Department of Atomic Energy (DAE), India is one of the leaders in developing and deploying NATs using neutrons, charge particles and photons as well as $\gamma$-ray spectrometry and neutron well coincidence counting (NWCC) for characterization of materials often non-destructively that are important for nuclear technology.

In view of continuous developments, it is appropriate to periodically review the progress made and evolve strategies to identify further areas of development and unique applications of radiotracers, radiations, and NATs. This prompted for the organization of symposia series on Nuclear Analytical Chemistry (NAC). The NAC-I, NAC-II and NAC-III symposia were held in Canada by Prof. A. Chatt. The NAC-IV symposium was organized at Bhabha Atomic Research Centre (BARC), Mumbai during November 15-19, 2010. The Fifth Symposium on Nuclear 


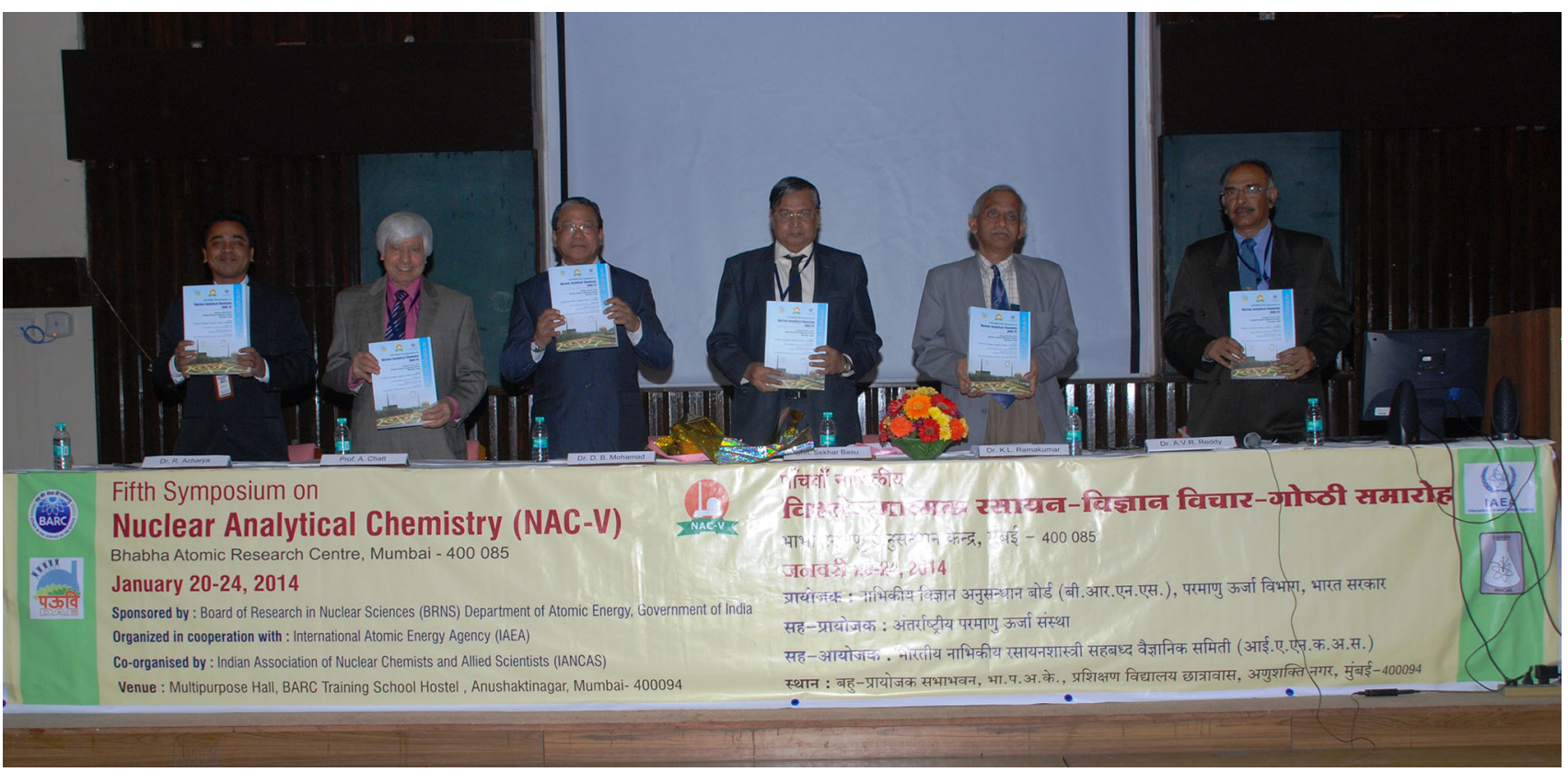

Fig. 1 Inaugural function of NAC-V symposium and release of book of abstracts: (Standing from right to left) Dr. A. V. R. Reddy (Convener and Head, ACD, BARC), Dr. K. L. Ramakumar (Chairman and Director, RC\&I Group, BARC), Shri Shekhar Basu

Analytical Chemistry (NAC-V) was organized at BARC during January 20-24, 2014. It was sponsored by the Board of Research in Nuclear Sciences (BRNS), Department of Atomic Energy (DAE), India. NAC-V was organized in cooperation with the International Atomic Energy Agency (IAEA) and co-organized by the Indian Association of Nuclear Chemists and Allied Scientists (IANCAS). More than 300 delegates including 18 scientists from abroad (Austria, Canada, Czech Republic, Japan, Mexico, Poland, Russia, Slovenia, South Korea, Thailand, UK, and USA) participated in NAC-V.

The NAC-V symposium was inaugurated by Shri Sekhar Basu, Director, BARC as the Chief Guest. Dr. D.B. Mohamad, IAEA was the Guest of Honour in Inaugural Function. It was followed by two plenary talks by (i) Dr. D.B. Mohamad, Deputy Director General, IAEA and (ii) Dr. B. Sur, Director, Nuclear Sciences Division, AECL, Canada. A one-day technical programme of NAC-V was conducted in K.C. College Arts, Science and Commerce, Mumbai on January 22, 2014 as a part of its Diamond Jubilee celebrations as well as to provide an opportunity to faculties, research scholars and students to participate and interact with the experts. Dr. R.K. Sinha, Chairman, Atomic Energy Commission (AEC) and Secretary, DAE, Government of India and Shri S.G. Markandeya, Ex-Controller of BARC and Scientific Secretary, BRNS, DAE were Chief Guest and Guest of Honour, respectively, at the one day program in K. C. College.
(Director, BARC), Dr. Daud B. Mohamad (Deputy Director General, IAEA), Prof. A. Chatt (Co-Chairman, Technical Committee, Dalhousie University), Dr. R. Acharya (Secretary and Scientific Officer, $\mathrm{RCD}, \mathrm{BARC})$

A large number of contributions were received from abroad and Indian academic Institutes and DAE Units. Besides two plenary talks, the Technical Program comprised of 25 invited talks and 10 invited short talks by experts in the field. The names of invited speakers were: Profs/Drs. A. V. R. Reddy, Amar Sinha, H. Naik, B. L. Ahuja, S. N. Jha, Alok Srivastava, Y. Nagame, H. Haba, C. R. Venkatasubramani, A. Chatt, S. Basu, T. Ohtsuki, A. Dash, H. J. Pant, A. K. Pandey, S. K. Aggarwal, J. Cantle, K. S. Pradeepkumar, R. R. Greenberg, B. Smodis, R. S. Dybczynski, S. C. Dash, B. S. Tomar, Hemlata K Bagla and R. Acharya, and invited short talk speakers were: Drs. G. M. Sun, T. Das, M. Fukushima, K. Takamiya, R. K. Dutta, S. Pavelka, M. Mohaptra, P. Sola and S. K. Sahoo. Contributed papers (240) were part of 15 technical sessions as oral and poster presentations. The scope of $\mathrm{NAC}-\mathrm{V}$ is reflected in the number of abstracts accepted in each category: (i) 21 in conventional and prompt gammaray activation analysis; (ii) 33 in alpha, X-ray and gammaray spectrometry; (iii) 16 in ion beam analysis; (iv) 46 in analytical chemistry in nuclear technology; (v) 11 in solid state nuclear track techniques; (vi) 33 in radioisotope production and applications; (vii) 9 in actinide and trace element speciation studies; (viii) 58 in environmental radioactivity; (ix) 5 in nuclear forensics and safety; and (x) 8 in QA/QC and uncertainty in measurements. Organizers presented 20 IANCAS awards for the best poster and oral paper presentations to young academics, scientists and 


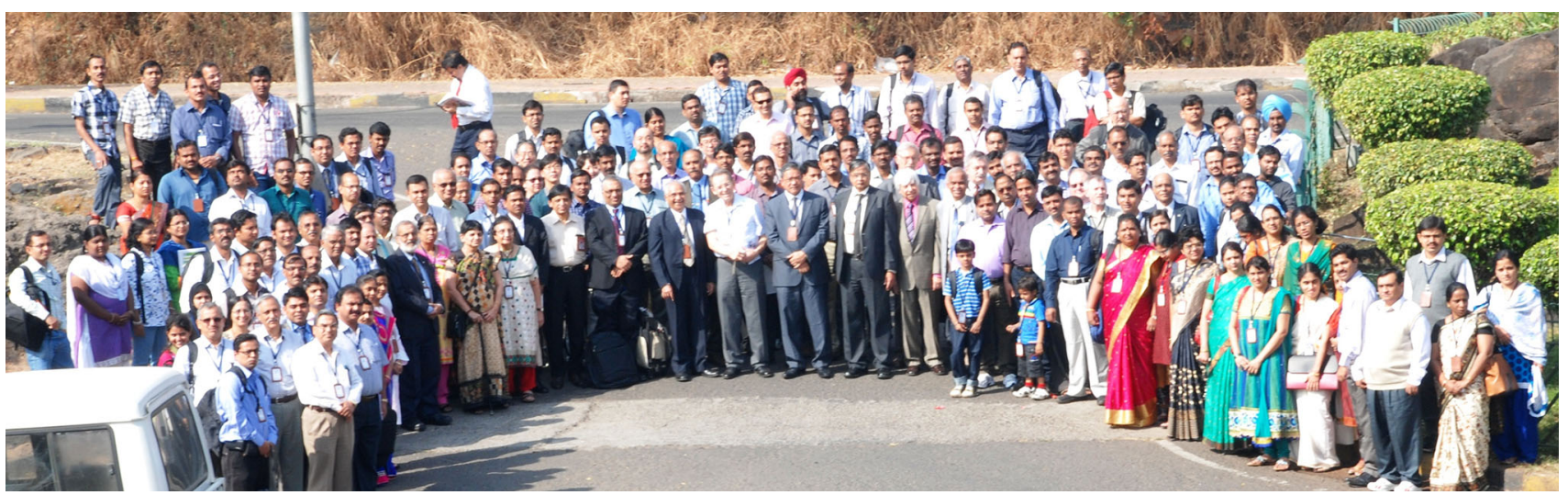

Fig. 2 Group photo of NAC-V participants

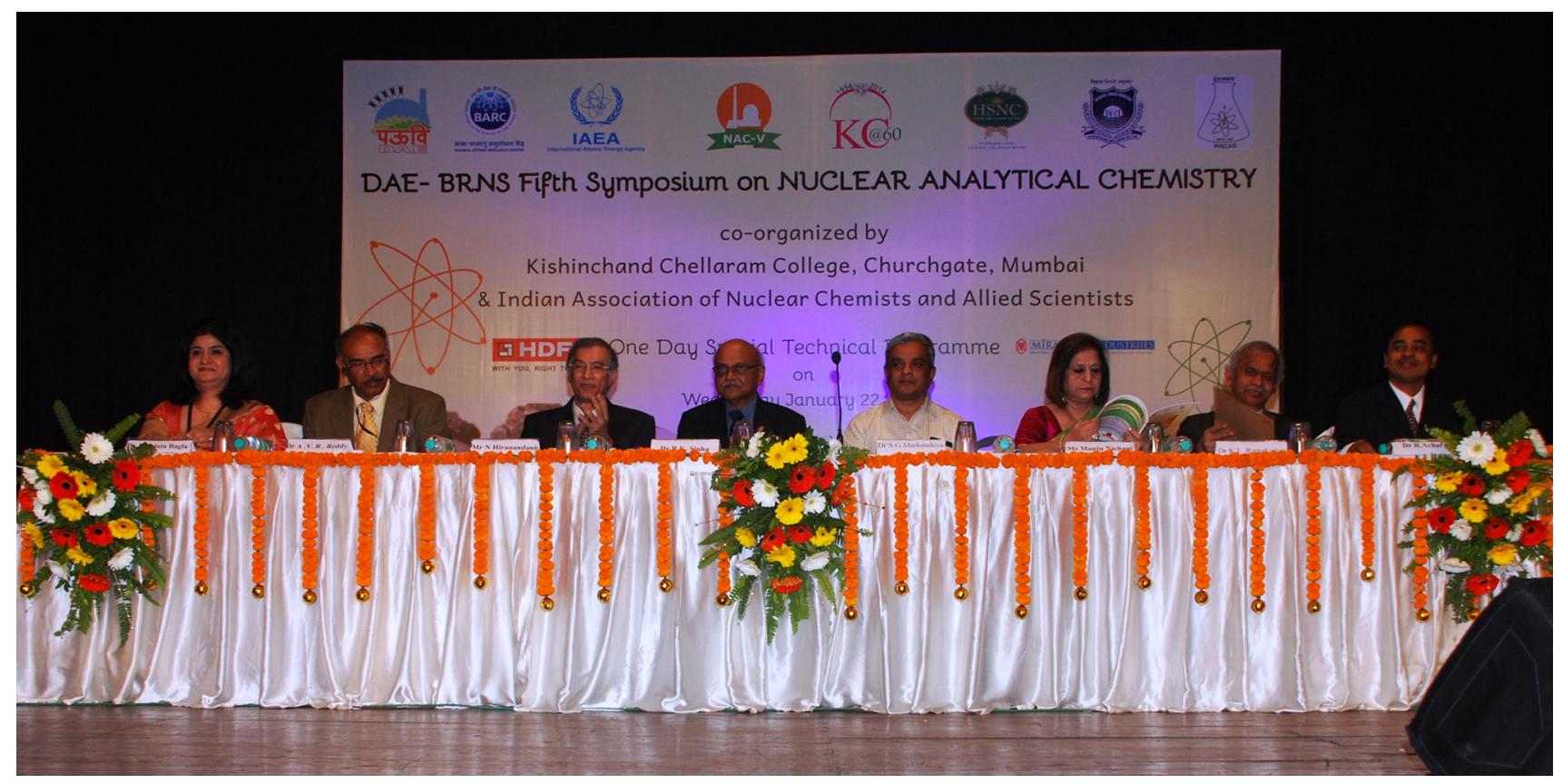

Fig. 3 Inauguration of one-day technical program of NAC-V at K. C. College, Mumbai: (Sitting from right to left) Dr. R. Acharya (Secretary), Dr. K. L. Ramakumar (Chairman), Dr. (Mrs) Manju Nichani (Principal, K. C. College), Dr. S. G. Markandeya (Former Controller, BARC), Dr. R. K. Sinha (Chairman, Atomic Energy

research students. Three photographs of NAC-V are given in Figs. 1, 2 and 3.

We received continuous support and guidance from authorities which enabled us to organize NAC-V. We profusely thank Dr. R. K. Sinha, Chairman, AEC for providing guidance and encouragement for organizing this symposium as Chairman of the Advisory Committee and giving a message. We are grateful to Shri Sekhar Basu, Director, BARC for his guidance and support and also for Inaugurating NAC-V as well as giving a message. We thank Prof. P. Rama Rao, Chairman, Board of Research in
Commission and Secretary, Department of atomic Energy, Government of India), Mr. Niranjan Hiranandani (President, H(S) N C Board), Dr. A. V. R. Reddy (Convener), Dr. Hemlata K. Bagla (Vice Principal, K C College and Local Convener)

Nuclear Sciences (BRNS), DAE for his encouragement. The organizers thank BRNS, DAE and IAEA for financial support. IANCAS is synonymous with the organization of symposia related to nuclear and radiochemistry in India, and we thank IANCAS for co-organizing NAC-V. Support and co-operation of Dr. K. L. Ramakumar, Director of Radiochemistry and Isotope Group, BARC as well as Chairman of the NAC-V Organizing Committee is gratefully acknowledged. We thank Dr. B. N. Jagatap, Director of the Chemistry Group and Dr. S. K. Aggarwal, Associate Director of the RC\&I Group, BARC for their constant 
Table 1 Titles and authors of full papers of NAC-V in Special Issue of JRNC

Sr. no. Title of paper Authors

1 Recent advances in ratio primary reference measurement procedures (definitive methods) and their use in certification of reference materials and controlling assigned values in proficiency testing

2 Applications of EDXRF and INAA techniques for studying impact of industries to the environment

3

Speciation of uranium in solids using time resolved photoluminescence technique

Estimation of indoor radon and the annual effective dose form building materials

Anticoincidence counting further improves detection limits of shortlived products by pseudo-cyclic instrumental neutron activation analysis

A feasibility study to measure low levels of boron in selected Canadian and Japanese foods by prompt gamma activation analysis using the JAEA JRR-3 facility

Evaluation of soil to tea plant elemental correlation using instrumental neutron activation analysis

Performance of digital gamma ray spectrometer for loss free counting and its application to NAA using short-lived radionuclides

Determination of aluminium contents in selected food samples by instrumental neutron activation analysis

10 Utilization of pneumatic carrier facility of Dhruva reactor for trace element determination by neutron activation analysis

11 Expanded uncertainties of preconcentration neutron activation measurements of extractable organo-chlorine, bromine and iodine compounds in bovine milk lipids

12 Estimation of uranium in geological rock samples by beta-gamma method and its comparison with pellet fluorimetry method

13 Application of $k_{0}$-based NAA for multielement determination in serpentines and associated minerals

14 Application of simulated standard spectra for the analysis of complex sample spectra from $\mathrm{NaI}(\mathrm{Tl})$ detectors

15 Assessment of elemental contamination in road dust using EDXRF

16 Geochemical peculiarities of marine sediment in coastal areas of India

17 Application of TXRF for burn leach test of TRISO coated $\mathrm{UO}_{2}$ particles

Determination of multi-element profiles of soil at Visakhapatnam using EDXRF technique

19 Depth profiling $\mathrm{Cr}$ in surface layers by ${ }^{52} \mathrm{Cr}(\mathrm{p}, \gamma)^{53} \mathrm{Mn}$ nuclear resonance reaction analysis

Determination of fluorine concentrations in soil samples using particle induced gamma-ray emission

21 Studies on changes in trace elemental content of serum of uterine cervix cancer patients using PIXE

22 Depth profiling of titanium using a resonance in ${ }^{48} \mathrm{Ti}(\mathrm{p}, \gamma)^{49} \mathrm{~V}$ nuclear reaction

Fluorimetric estimation of U(VI) in the presence of a large excess of Th(IV)

24 Estimation of free acidity in some hydrolysable metal ions present in reprocessing streams by fiber optic aided spectrophotometry
R. S. Dybczyński, H. Polkowska-Motrenko, E.Chajduk, B. Danko, M. Pyszynska

R. K. Dutta, S. Sarkar, S. S. Ram, M. Sudarshan, R. Acharya, A. V. R. Reddy

M. Mohapatra, V. Natarajan

P. Sola, W. Srinuttakul, S. Laoharojanaphand, N. Suwankot

W. Zhang, A. Chatt

\section{Fukushima, H. Matsue, A. Chatt}

Rupali A. Lagad, K. B. Dasari, D. Alamelu, R. Acharya, S. K. Aggarwal

R. Acharya, K. B. Dasari, D. Chandra Shekhar, T.

P. Chaturvedi, P. K. Pujari

B. B. Nanda, R.R. Biswal, R. Acharya, J. S. B. Rao, P. K. Pujari

R. Acharya, K. K. Swain, A. D. Shinde, N. S. Bhamra, K. Chakrabarty, C. G. Karhadkar, Tej Singh, Y. S. Rana, P. K. Pujari, D. K. Shukla, A. V. R. Reddy

K. Isaac-Olive, A. Chatt

Rita, M. A Nayeem, Gaur Diwakar, G. B Rout, B. K. Pandey, A.K. Sarangi

P.V. Nagendra Kumar, N. Suresh Kumar, R. Acharya,

L. Krishna Reddy, A. V. R. Reddy

S. Anilkumar, K. Narayani, A.K. Verma, Rajvir Singh, K. S. Pradeepkumar

V. Saradhi, Sandeep Police, G. G. Pandit

S. S. Gothankar, S. K. Jha and R. M. Tripathi

Kaushik Sanyal, Sangita Dhara, S. Sanjay Kumar, N.

L. Misra,

P. K. Mollick, P. T. Rao, R. Venugopalan, Rajesh V. Pai,

N. Kumar, S. K. Mukerjee, J. K. Chakravartty, S.

K. Aggarwal

Sandeep P, Kothai P, C. B. Dusane, S. K. Sahu, G. G. Pandit

Pritty Rao, S. Vikram Kumar, Sanjiv Kumar

A. Srivastava, S. Chhillar, N. Kaur, D. Singh, R. Acharya, P. K. Pujari

P. Sarita, G. J. Naga Raju, S. BhulokaReddy

G. L. N. Reddy, S. Vikram Kumar, J. V. Ramana, Sanjiv Kumar

S. Maji, Satendra Kumar, K. Sankaran

S. Ganesh, P.Velavendan, N. K. Pandey, U. Kamachi Mudali, R. Natarajan 
Table 1 continued

Sr. no. Title of paper Authors

25 Analytical application of poly[dibenzo-18-crown-6]for column chromatographic separation of $\mathrm{Nd}(\mathrm{III})$ from $\mathrm{Ce}(\mathrm{III}), \mathrm{U}(\mathrm{VI})$ and other elements

26 Development of methodology for the determination of Boron in $\mathrm{ThO}_{2}$ employing spectrophotometry

27 Synthesis and evaluation of a phenylbenzothiazole-based $99 \mathrm{mTc}(\mathrm{CO}) 3$ - radiotracer for possible application in imaging of $\beta$ amyloid plaques in Alzheimer's disease

28 Formulation and radiochemical evaluation of a freeze-dried mixed peptide kit for the preparation of ${ }^{68} \mathrm{Ga}$-labeled peptides for PET imaging of somatostatin receptor positive neuroendocrine cancers

29 Determination of calcium and iron in silicon and uranium silicide using Ion chromatography

30 Determination of boron concentration in borosilicate glass, boron carbide and graphite samples by conventional wet-chemical and nuclear analytical methods

31 Standardisation of radioimmunoassay for human insulin employing magnetizable cellulose particles

32 On-site monitoring of uranium in low level liquid waste streams using U-Br-PADAP strip indicator paper technique

33 Radon, thoron and their progeny concentration variations in dwellings of Gogi region, Yadgir District of Karnataka, India

34 Thoron interference in radon exhalation rate measured by solid state nuclear track detector based can technique

35 Neutron dose estimation for ${ }^{1} \mathrm{H}+{ }^{9} \mathrm{Be}$ and ${ }^{1} \mathrm{H}+{ }^{12} \mathrm{C}$ reactions at $20 \mathrm{MeV}$ proton energy via LET spectrometry using CR-39 detectors

36 Measurement of ${ }^{222} \mathrm{Rn}$ and ${ }^{220} \mathrm{Rn}$ decay product deposition velocities using SSNTD based passive detectors

37 Preparation and deployment of indigenous ${ }^{125}$ I- seeds for the treatment of prostate cancer: Dawn of prostate brachytherapy in India

${ }^{14} \mathrm{CO}_{2}$ labeling: A reliable technique for rapid measurement of total root exudation capacity and vascular sap flow in crop plants

39 Residence time distribution study in a pilot-scale gas-solid fluidized bed reactor using radiotracer technique

Single vial kit formulation for preparation of PET radiopharmaceutical: ${ }^{68} \mathrm{Ga}$-DOTA-TOC

41 Investigation of liquid-solids fluidized bed of different particle size through radioactive particle tracking techniques

42 Nano-crystalline zirconia: A viable adsorbent for the column chromatographic separation of ${ }^{58} \mathrm{Co}$ from neutron irradiated nickel targets

43 Studies on evaluation of modified TRUEX solvent for the partitioning of minor actinides

44 Isolation, screening and characterization of uranium microremediable actinomycetes from fallen leaves of Azadirachta indica in Western Ghats

Tritium measurement in the Western Caucasus

46 Study of radon, thoron and their progeny levels in indoor environment of Firozabad city in U.P., India

47 Study on the spatial distribution of ${ }^{137} \mathrm{Cs}$ content in bottom sediment and benthic species of Mumbai off coast
S. N. Lad, B. S. Mohite

P. S. Ramanjaneyulu, K. L. Pandey, M. K. Saxena, B. S. Tomar, K. L. Ramakumar

Drishty Satpati, Aruna Korde, H. D. Sarma, Sharmila

Banerjee

Tapas Das, Mohini Bhadwal, H. D. Sarma, Sharmila Banerjee

M. K. Das, V. V. Raut, S. B. Deb, S. Jeyakumar, M.

K. Saxena,

B. S. Tomar

K. Venkatesh, Sumit Chhillar, Granthali S. Kamble, Shailaja P. Pandey, Manisha Venkatesh, Sanjukta A. Kumar, Sanjiv Kumar, R. Acharya, P. K. Pujari, A. V. R. Reddy

R. R. Rasmi, K. B. Shenoy, Jayula Sarnaik, V. B. Kadwad, H. M. Somashekarappa, N. Sivaprasad

S. Ganesh, P. Velavendan, N. K. Pandey, U. Kamachi

Mudali,

R. Natarajan

Avinash P R, S Rajesh, B R Kerur, Rosaline Mishra

B. K. Sahoo, T. K. Agarwal, J. J. Gaware, B. K. Sapra

G. S. Sahoo, S. P. Tripathy, S. Paul, S. D. Sharma, D.

S. Joshi,

T. Bandyopadhyay

R. P. Rout, R. Mishra, R. Prajith, Jalaluddin S., B. K. Sapra

Sanjay Kumar Saxena, Archana Mukherjee, Yogendra Kumar, Ramu Ram, A. S. Tapase, Vivek J. Anand, Ashutosh Dash

Bhupinder Singh, Sumedha Ahuja, Renu Pandey, RK Singhal

H. J. Pant, V. K. Sharma, Sunil Goswami, J. S. Samantray, I. N. Mohan, Tirupathi Naidu

Archana Mukherjee, Usha Pandey, Rubel Chakravarty, Haladhar Dev Sarma, Ashutosh Dash

Shubham Jain, Priyam Saraswat, Varsha Jain, Harish J. Pant and Rajesh K. Upadhyay

K. V. Vimalnath, S. Priyalata, S. Chakraborty, Ramu Ram, Rubel Chakravarty, Ashutosh Dash

Arijit Sengupta, M. S. Murali, P. K. Mohapatra

Mrinalini J Singh, S. Padmavathy

T. Tsvetkova, I. Nevinsky, V. Nevinsky, B. Suiatin

Mukesh Kumar, Anshu Agrawal, Rajesh Kumar

S. Sugandhi, V.M. Joshi, S. K. Jha, R. M. Tripathi 
Table 1 continued

\begin{tabular}{|c|c|c|}
\hline Sr. no. & Title of paper & Authors \\
\hline 48 & $\begin{array}{l}\text { Distribution of }{ }^{238} \mathrm{U},{ }^{226} \mathrm{Ra},{ }^{232} \mathrm{Th} \text { and }{ }^{40} \mathrm{~K} \text { in soil samples around } \\
\text { Tarapur, India }\end{array}$ & C. B. Dusane, S. Mishra, S. K. Sahu, G. G. Pandit \\
\hline 49 & $\begin{array}{l}\text { Optimizations of teflon embedded } \mathrm{CaSO}_{4} \text { : Dy based TLD for } \\
\text { environmental monitoring applications }\end{array}$ & $\begin{array}{l}\text { R. A. Takale, S. K. Sahu, M. Swarnkar, P. G. Shetty, G. } \\
\text { G. Pandit }\end{array}$ \\
\hline 50 & $\begin{array}{l}\text { Distribution of uranium \& thorium in fractionated sediment samples } \\
\text { obtained from different locations across Thane creek area, Mumbai, } \\
\text { India }\end{array}$ & Sukanta Maity, S. K. Sahu, G. G. Pandit \\
\hline 51 & $\begin{array}{l}\text { Studies on sorption of uranium on chitin-a solid state extractant- } \\
\text { application for removal of uranium from ground water }\end{array}$ & Beena Sunilkumar, G. Chakrapani \\
\hline 52 & $\begin{array}{l}\text { Occurrence of the radionuclides in groundwater of crystalline hard rock } \\
\text { regions of central Tamil Nadu, India }\end{array}$ & $\begin{array}{l}\text { C. Thivya, S. Chidambaram, K. Tirumalesh, M. V. Prasanna, } \\
\text { R. Thilagavathi and M. Nepolian }\end{array}$ \\
\hline 53 & $\begin{array}{l}\text { Assessment of environmental radioactive elements in groundwater in } \\
\text { parts of Nalgonda district, Andhra Pradesh, South India using } \\
\text { scintillation detection methods }\end{array}$ & $\begin{array}{l}\text { Tirumalesh Keesari, Hemant V. Mohokar, Bijay Kumar } \\
\text { Sahoo, Mallesh G. }\end{array}$ \\
\hline 54 & $\begin{array}{l}\text { Radiological measurement of phosphate rock and phosphogypsum from } \\
\text { fertilizer industries in India }\end{array}$ & $\begin{array}{l}\text { S. J. Sartandel, S. V. Bara, S. Chinnaesakki, S. K. Jha, } \\
\text { R. M. Tripathi }\end{array}$ \\
\hline
\end{tabular}

support. Thanks are due to Shri S. G. Markandeya, Former Scientific Secretary of BRNS and Ex-Controller of BARC for his keen interest in this symposium. We take this opportunity to thank Prof. A. Chatt of Dalhousie University, Canada and Co-Chairman of the Technical Committee for his support and enthusiasm in organizing NAC-V at BARC. We thank all the members of the Advisory Committee, Organizing Committee, Technical Committee and other committees for their valuable support during the formulation of the technical content of the symposium. We are fortunate to have experts in various committees who shared their expertise. We are grateful to the members of Local Organizing Committee (LOC), and Chairman, LOC, Dr. P.K. Pujari, Head, Nuclear Chemistry Section, RCD, BARC, and Dr. L. Varshney, Head, RTDD, BARC (Chairman, Finance Committee), who have worked with dedication in organizing this symposium. We thank Dr. K.K. Swain, Dr. D. Alamelu, Dr. S. Jeyakumar, Dr. S. K. Thulasidas, Dr. A. C. Deb, Shri K. Venkatesh, Dr. K. V. V. Nair, Dr. R. Tripathi, Dr. S. Sodaye, Shri K. C. Jagadeesan, Mr. D. B. Paranjape, Dr. Pranaw Kumar, Dr. P. S. Remya Devi, Dr. A. K. Satpati, Mr. R. G. Dalvi and Dr. K. B. Dasari who have contributed immensely for the success of NAC-V in various capacities. We thank our dearest colleague and technical committee member (Late) Dr. P. N. Pathak, RCD, BARC for his immense contributions in various activities of NAC-V including review of full papers and condole with heavy hearts his untimely demise. We thank Dr. Hemlata K Bagla, Vice Principal and Dr. Manju Nichani, Principal, K. C. College and College authorities and team of volunteers for organizing one day technical programme of NAC V. Sincere and dedicated efforts of Shri Sharad Nalawade in composing theabstract book are acknowledged. We thank Shri Sharad Nalawade, Shri Vishal N. Koli and Prefect Prints for their effort in printing and publishing the abstract book. Thanks are due to administrative staff of Director, BARC, RC\&I Group, Chemistry Group, RCD, ACD, HRDD, and BARC Training School Hostel (TSH) of BARC. Thanks are due to the reviewers of pre-selected manuscripts for sparing their time.

We are thankful to the Journal of Radioanalytical and Nuclear Chemistry (JRNC) for agreeing to publish a few selected full papers for maintaining a high quality in a Special Issue on NAC-V. We followed a rigorous procedure of pre-selecting manuscripts which were then critically reviewed by two or three expert reviewers in the field as per the guidelines set by JRNC. We are happy that 54 full manuscripts have been accepted in JRNC for publication. Table 1 gives the list of 54 papers (titles and authors) presented in various technical sessions of NAC-V. We thank all the reviewers from India and abroad as well as all the authors for their timely support in bringing out this Special Issue. The Guest Editors thank Dr. Zsolt Revay (Editor-in-Chief), Prof. A. Chatt (Editor, Special Issues), and Dr. Tibor Kocsor (Associate Editor) of Journal of Radioanalytical and Nuclear Chemistry for their continuous guidance and support in bringing out this Special Issue of JRNC containing papers of NAC-V. 